\title{
IV.
}

\section{BERICHTIGUNG und NACHTRAG}

zu dem Aufsatz ron Dr. Meinhard Schmidt, .Zur operativen Behandlung der obturirenden Prostatahypertrophie ${ }^{\star}$ in Band XXVIII. S. 391 dieser Zeitschrift.

Auf Seite 392, Zeile 3 von unten muss es in meiner Arbeit heissen „H.'s (H arrison's) Mittheilungen" statt „Nr. 6".

Ich benutze die Gelegenheit, um nachträglich mitzutheilen, dass mein Operirter bis jetzt völlig gesund geblieben ist, so dass sein $\mathrm{Zu}$ stand sich nach seiner Entlassung noch weiter gebessert hat. Ich sah ihn vor Kurzem wieder und fand ihn sehr vortheilhaft verändert. Er ist wohlgenährt geworden, kräftig und sieht blühend aus. Hat sich bei den Erntearbeiten energisch betheiligen können. Die Urinentleerung ist ganz normal und beschwerdefrei. Auch Nachts wird der Mann jetzt nicht mehr gestört und kann durchschlafen. Ich glaube, dass der therapeutische Erfolg in dem Falle alles geleistet, was von ihm zu verlangen war, und dass, selbst angenommen, dass die Heilung keine dauernde bleiben dürfte, der Operirte für die mit der Behandlung verknupften ausgestandenen Beschwerden - von den Opfern an Zeit und Geld nicht zu reden - aufs Reichlichste entschädigt ist.

Cuxharen, 26. October 1888.

M. S. 